\title{
Usability testing of multimodal feedback interface and simulated collision-avoidance power wheelchair for long-term-care home residents with cognitive impairments
}

\author{
Rosalie H. Wang, PhD, BSc (OT); ${ }^{1-3 *}$ Alex Mihailidis, PhD, PEng; ${ }^{1-5}$ Tilak Dutta, PhD(c), MASc; ${ }^{1,5}$ Geoff R. \\ Fernie, PhD, PEng ${ }^{1-6}$ \\ ${ }^{1}$ iDAPT, Toronto Rehabilitation Institute, Toronto, Canada; ${ }^{2}$ Graduate Department of Rehabilitation Science, ${ }^{3}$ Institute of \\ Biomaterials and Biomedical Engineering, ${ }^{4}$ Department of Occupational Science and Occupational Therapy, ${ }^{5}$ Department \\ of Mechanical and Industrial Engineering, and ${ }^{6}$ Department of Surgery, University of Toronto, Toronto, Canada
}

\begin{abstract}
Many older adults in long-term-care homes have complex physical and cognitive impairments and have difficulty propelling manual wheelchairs. Power wheelchair use is restricted owing to safety concerns. Power wheelchairs with collisionavoidance features are being developed to enable safe and independent mobility; however, a paucity of information exists on interface features to help users navigate away from obstacles. We developed a system combining an interface with auditory, visual, and haptic feedback and a simulated collision-avoidance power wheelchair. This device allowed the investigator to stop movement of the power wheelchair when users approached obstacles and to deliver feedback to help them navigate. Five long-termcare home residents with mild or moderate cognitive impairments evaluated device usability, which included effectiveness, efficiency, and user satisfaction. Each resident used the device for six $1 \mathrm{~h}$ sessions. Observations, feedback interviews, and outcome questionnaires were completed during and after the sessions. We found the device effective in enabling residents to achieve basic driving tasks and self-identified indoor mobility goals. Furthermore, residents perceived workload to be low and were satisfied with the device. Residents also felt that the feedback was useful to help them navigate away from obstacles.
\end{abstract}

Key words: auditory feedback, cognitive impairment, collisionavoidance power wheelchair, haptic, joystick, long-term-care home, multimodal feedback, older adult, power mobility, smart power wheelchair, usability, user interface, user satisfaction, visual feedback.

\section{INTRODUCTION}

Independent mobility is essential in the quality of life of older adults living in institutions [1]. Mobility can be restricted owing to multiple chronic conditions such as arthritis, diabetes, stroke, congestive heart failure, and Alzheimer disease or other forms of dementia [2]. Approximately 50 percent of older adults in Canadian institutions use wheelchairs for mobility [3]; however, residents are often unable to use their wheelchairs to move independently. Sources cite a wide range of percentages of residents who are able to self-mobilize in their wheelchairs, from as low as

\footnotetext{
Abbreviations: DS $=$ driving session, ISO = International Organization for Standardization, MMSE = Mini-Mental State Examination, NASA-TLX $=$ National Aeronautics and Space Administration Task Load Index, PIADS = Psychosocial Impact of Assistive Devices Scale, PIDA = Power-Mobility Indoor Driving Assessment, QUEST = Quebec User Evaluation of Satisfaction with Assistive Technology.

* Address all correspondence to Rosalie $\mathbf{H}$. Wang, PhD, BSc (OT); Intelligent Assistive Technology and Systems Laboratory, Department of Occupational Science \& Occupational Therapy, University of Toronto, 160-500 University Ave, Toronto, ON, M5G 1V7 Canada; 416-946-8573; fax: 416946-8570. Email: wang.rosalie@torontorehab.on.ca

DOI:10.1682/JRRD.2010.08.0147
} 
4 to 14 percent [4] to 50 percent [5]. Hence, mobility independence is reduced or not achieved for many residents.

Power wheelchairs can improve the independence and quality of life of people with physical mobility problems [6-8]. Individuals with significantly restricted mobility and impaired vision, perception, and cognition do not always have access to power mobility [9]. In the institutional setting, an important reason for limited access is driving safety concerns, such as possibly striking older adult residents who are walking and already at high risk of falling [10-11]. For many, currently available power wheelchairs are unable to accommodate their abilities and enable independent mobility [12-13].

Modified or "smart" power wheelchairs with collisionavoidance and navigation assistance features are being developed to enable safe and independent mobility in users with complex physical, sensory, and cognitive limitations. A comprehensive review of smart wheelchair projects is provided by Simpson [14]. With a few exceptions [15-18], the majority of advanced power wheelchairs have not been designed for long-term institutional-care residents with cognitive impairments. Moreover, only two systems have been tested with this targeted population. Swartz and Mihailidis presented a system in a pilot study with longterm-care home residents with dementia [18]. This system used a stereovision camera as a sensor and auditory prompts to direct users away from nearby obstacles. Residents tested the power wheelchair without the system in place for one set of three trials of an obstacle course on 1 day and repeated the same trial another day with the system in place. Most residents found no difference in the perception of safety or likability of the power wheelchair with or without the anticollision system. Residents identified that with the system in place, the wheelchair stopped before obstacle contact, but many also felt frustrated when driving with the anticollision system in place.

The system described by Wang et al. [17] was tested with long-term-care home residents with mild or moderate cognitive impairments related to dementia who were not permitted to drive a power wheelchair. The testing lasted up to several months, depending on the resident. This system included a contact sensor skirt, such that movement of the power wheelchair gently stopped if contact was made with an obstacle. The user interface consisted of a standard joystick controller, indicator lights, and embedded control logic that only allowed movement in directions away from obstacles if power wheelchair movement stopped. The indicator lights were a set of six directional arrows mounted in front of the joystick that lit up to visually display the directions of allowed movement. However, residents did not notice the lights or did not understand their meaning. Additionally, joystick movement was allowed in all directions even when power wheelchair movement was not. Only movement of the joystick to directions programmed into the logic produced movement of the power wheelchair. This was confusing for users, particularly when they did not recognize obstacles such as those low to the ground or in the back, but the sensors did. Users then moved the joystick randomly with frustration to find a direction that allowed for power wheelchair movement. The user interface was difficult and frustrating for users because of ineffective prompts or feedback for correct and incorrect joystick movements. Findings indicated that while the concept of a collisionavoidance power wheelchair was supported, use of the device as primary mobility was low for the residents tested, one reason being poor usability of the interface.

Most of these new technologies are in development. A paucity of information exists on interface designs and specifications to help users, especially those with cognitive impairments, drive power wheelchairs with collisionavoidance features. General principles for the design of technology usable by people with dementia have been outlined [19-20]. Maki and Topo [19] and Orpwood et al. [20] indicate that technology needs to-

- Be designed to support user choices and varying abilities.

- Be simple and intuitive to use.

- Provide prompting for the correct sequence of user actions.

- Provide appropriate feedback for actions (particularly positive feedback).

- Have information presented multimodally (auditory, visual, and tactile) to add redundancy in communicating needed information.

- Require minimal or no new learning to limit confusion and minimize errors when people use the device.

- Require low physical effort.

Joysticks are the most common input interface for power wheelchairs [12]. One study has suggested that use of a joystick to operate a moving device has low cognitive requirements because of the overt cause-and-effect link [21]. Interface adaptations have been made to compensate for physical limitations, including decreased upper-limb strength or range of motion, spasticity, or tremor [22-23]. Haptic or force feedback joysticks have been used in collision-avoidance systems to help users navigate away from obstacles [24-26]. Haptic interfaces interact with a 
user's touch and kinesthetic systems through force or other mechanical stimuli [27] and passively or actively guide the user away from obstacles. The technologies have been tested in laboratory settings with computer simulation or virtual systems and subjects without physical or cognitive disabilities [25-26] and in a virtual reality environment with adults with cerebral palsy or postpolio syndrome [24].

The application of multimodal interfaces to provide feedback and guide users to specific actions is relevant to help them operate new power wheelchairs. These interfaces include different sensory outputs, mostly auditory and visual and some tactile, to support the use of various devices or applications [28]. User performance may be improved by the incorporation of multiple sensory channel outputs offering redundant information (to compensate for information that may be missed), creation of synergistic effects (that augment or heighten the impact of individual modalities), or widening of the window for information to be received and used [28]. This multisensory approach may be particularly useful for older adults because sensory processing with single channels such as hearing and vision declines with age, and evidence shows that multisensory input potentially compensates for declines in single-sensory channels with aging [29]. Combined auditory feedback and visual feedback have been tested with some success in other applications, including COACH (Cognitive Orthosis for Assisting with Activities in the Home), aimed to assist long-term-care home residents with dementia to complete hand washing or other activities [30]. Multimodal interfaces also have significant potential to help users drive automobiles safely [31-32].

Specifications for suitable interface designs and feedback systems will be increasingly important as testing of new collision-avoidance power wheelchairs progresses to clinical populations. We sought to develop a joystick interface with multimodal feedback for use with future collision-avoidance power wheelchairs. In this study, we evaluated the usability of the interface and a simulated collision-avoidance power wheelchair with long-termcare home residents with mild and moderate cognitive impairments. The device was termed "simulated collisionavoidance” because it mimicked features that a power wheelchair in the future may have. With the simulation, the investigator operated in-built functions that resulted in the collision avoidance. Usability according to the International Organization for Standardization (ISO) (ISO 9241-11: Guidance on Usability [1998]) is "the extent to which a product can be used by specified users to achieve specified goals with effectiveness, efficiency, and satisfaction in a specified context of use" [33], where effectiveness is "being able to complete a task," efficiency is "the amount of effort required to complete the task," and user satisfaction is "the degree to which the user was happy with his or her experience while performing the task" [33]. We hypothesized that the device will be-

1. Effective: Residents will be observed to be able to perform self-identified mobility goals and satisfactorily perform driving tasks from the Power-Mobility Indoor Driving Assessment (PIDA) [34].

2. Efficient: Residents will be able to operate the power wheelchair with the user interface within six $1 \mathrm{~h}$ driving sessions (DSs) as assessed using the PIDA, and residents will report a low level of workload on the National Aeronautics and Space Administration Task Load Index (NASA-TLX) [35].

3. User-satisfying: Residents will report satisfaction with the device and satisfaction and positive well-being on the Quebec User Evaluation of Satisfaction with Assistive Technology (QUEST) and the Psychosocial Impact of Assistive Devices Scale (PIADS) [36-37] associated with the use of the device.

\section{METHODS}

We used a concurrent mixed methods design, integrating quantitative and qualitative approaches [38]. Data sources included quantitative assessments and questionnaires, field notes from observations and resident comments during DSs, and interviews.

\section{Setting}

We recruited residents from two residences in Toronto, Canada. These residences offered $24 \mathrm{~h}$ nursing care and personal-care assistance. One site was a nonprofit retirement residence (107 residents) and long-term-care center (120 residents). Accommodations in the long-term-care side were private (own bathroom), semiprivate (two beds to a room, shared bathroom) or basic (four beds to a room, shared bathroom). The second site was a long-term-care center with 128 residents. The center was affiliated with a large academic hospital and managed by a contracted longterm-care service provider. Eighty rooms were private (own bathroom) and forty-eight rooms were standard (own room, bathroom shared between two residents). 


\section{Device Setup for Testing}

A commercially available midwheel drive Nomad power wheelchair from Dynamis Mobility (Barrie, Canada) was equipped with a modified joystick interface connected by way of a wire (3 $\mathrm{m}$ in length) to a laptop computer (running Windows 98 and MS-DOS). All hardware and software for the study were custom-developed (iDAPT; Toronto Rehabilitation Institute, Canada). Figures 1 and $\mathbf{2}$ show the setup of the device for testing. With this device, an investigator took the place of the sensors and intelligence (sensor input processing and decision making for navigation directions) that comprised the collision-avoidance feature that may be part of future power wheelchairs. When a user approached an obstacle and contact was imminent, the investigator pressed a marked programmed key on the computer keyboard that corresponded to the location of the obstacle near the power wheelchair. Pressing one of the marked keys stopped movement of the power wheelchair

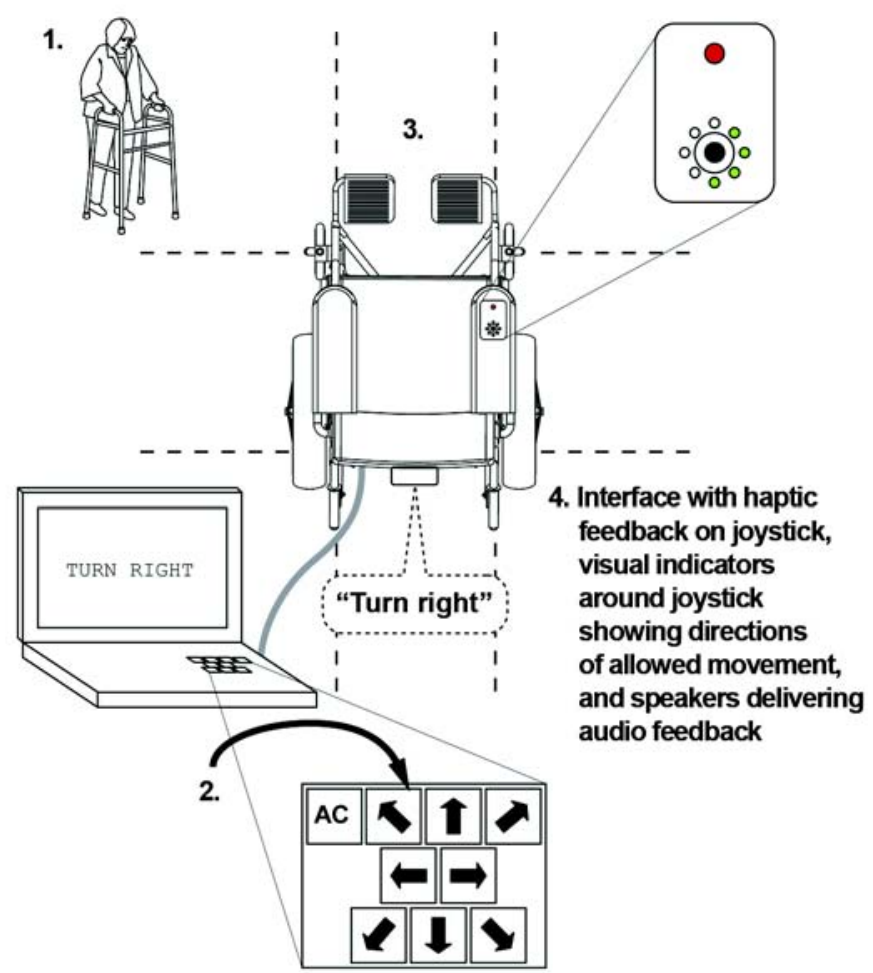

Figure 1.

Setup and operation of simulated collision-avoidance power wheelchair with multimodal feedback. Dashed lines mark eight obstacle zones. "AC" denotes key for "All Clear" command. (1) Obstacle at front left side; (2) investigator presses key on computer that corresponds to location of obstacle; (3) power wheelchair movement stops; and (4) delivery of auditory, visual, and haptic feedback. and automatically delivered three modes of feedback (auditory, visual, and haptic) that indicated the preferred directions of movement away from the obstacle. When the user moved the power wheelchair away from the obstacle, the investigator pressed the key marked "All Clear" and all movement directions were then indicated to be available.

Because different combinations of movement directions were possible to navigate away from an obstacle located around the periphery of the power wheelchair, the directions of joystick and power wheelchair movement were divided into eight zones (Figure 1). The safest preferred combinations of navigation directions for an obstacle located in the eight zones were programmed into the logic of the interface software. The investigators determined the preferred combinations during pilot testing, whereby they tested different obstacle or combinations of obstacle locations to identify the movement directions to best navigate away.

The user interface was simple in appearance, consisting of a power on-off button and a proportional control joystick (Figure 3). The three feedback modes delivered

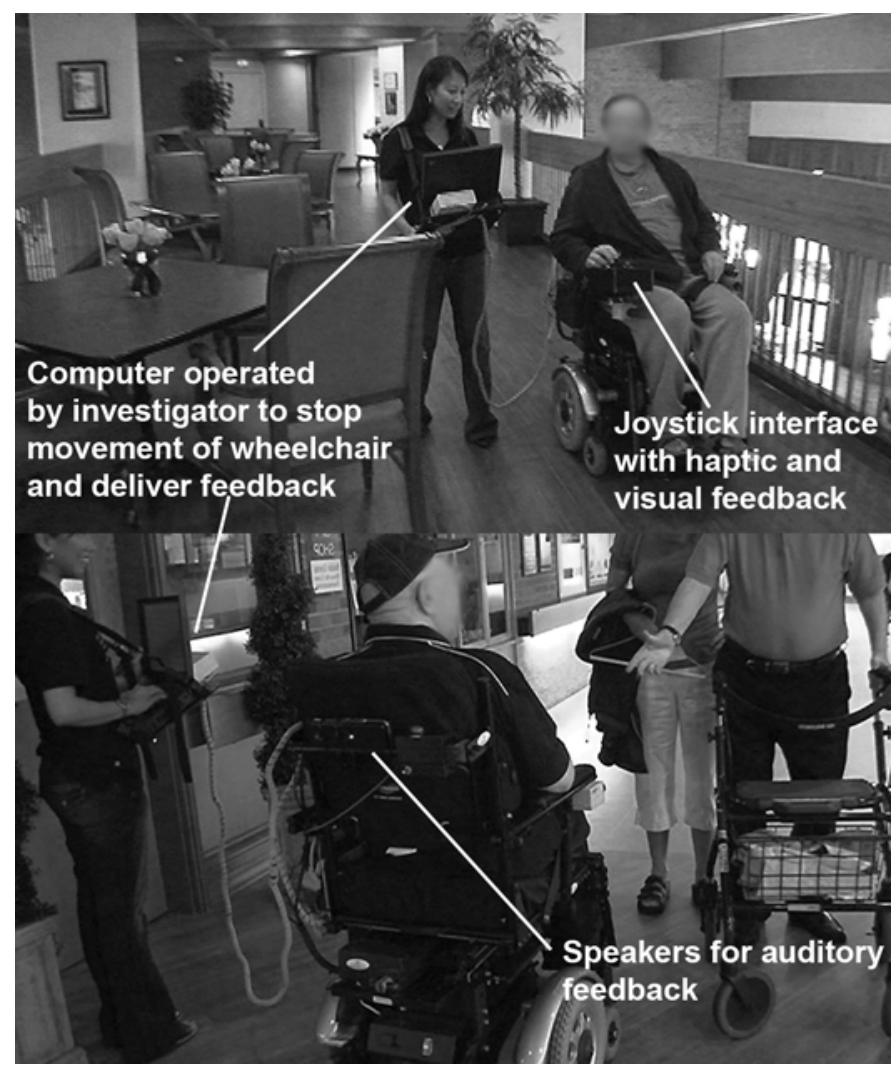

Figure 2.

Testing simulated collision-avoidance power wheelchair with multimodal feedback. 


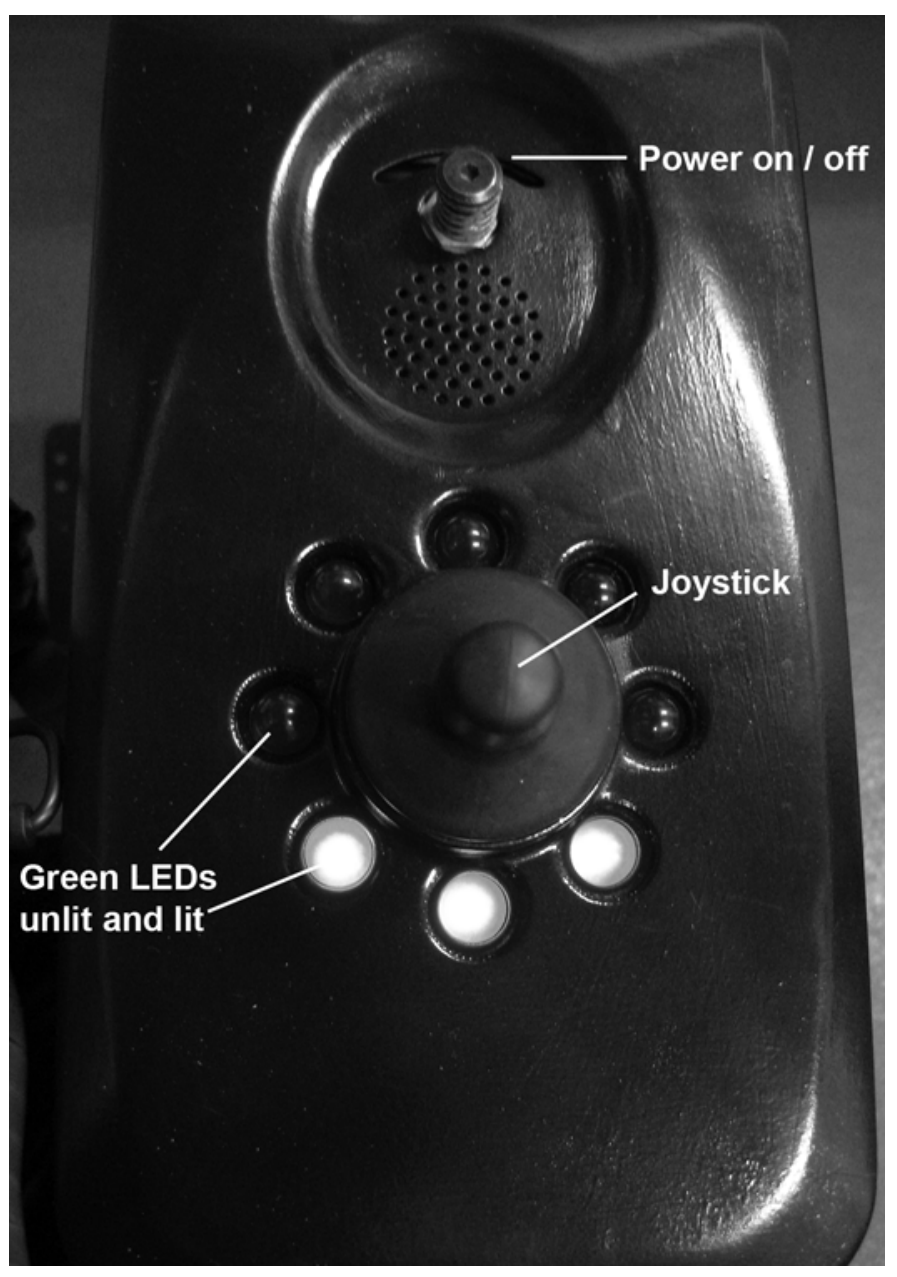

Figure 3.

Top view of user interface. Eight large green light-emitting diodes (LEDs) surround joystick and provide visual feedback by indicating directions of allowed movement.

together were aimed to provide consistent, immediate, and readily identifiable feedback for driving. Prerecorded auditory prompts gave four simple driving directions, "go forward," "turn right," "turn left," and "go back," and an "All Clear” prompt. The auditory prompts aimed to simplify the verbal directions as much as possible, in this case, one-step rather than two-step directions. From our previous experience, we identified that the two-step directions that investigators gave were poorly understood by the residents. Auditory prompts were recorded with a woman's voice and delivered by way of a small speaker mounted at the upper back of the power wheelchair. Eight large green light-emitting diodes provided visual feedback surrounding the joystick as shown in Figure 3.
We implemented haptic feedback to allow eight possible movement directions. With haptic feedback, the user's joystick movements were restricted in the directions of obstacles and only movement away from obstacles was allowed. We thought that users should have as many directional options as possible to navigate away from obstacles, rather than restricting the movement to four quadrants. If the residents moved the joystick slightly off from the direction that the auditory prompt suggested and that direction was allowable, they would still be able to navigate successfully away from the obstacle. Haptic feedback was generated with eight radio-controlled servomotors mounted around the base of the joystick. Refer to Figure 4 for details. When activated, a servomotor rotated a small plate that in turn moved a bar toward the joystick. The joystick was attached to a plate that interfaced with the bars. When a combination of bars was activated, the user could not move the joystick in those directions, preventing the movement of the wheelchair in the same directions.

The distance from obstacles at which the investigator stopped movement of the power wheelchair depended on the stopping distance of the power wheelchair (which depended on the speed at which it was moving) and the response time of the investigator. The forward driving speed was set to a maximum of $1.8 \mathrm{~km} / \mathrm{h}(1.1 \mathrm{mi} / \mathrm{h})$, which was almost half an average walking speed. At this maximum speed, we tested the stopping distance of the power wheelchair to be $40 \mathrm{~cm}$ (15.75 in.). The driving speed of the user was typically slower while driving in tight spaces, such as inside the bedroom or around the dining room, so shorter stopping distances were tolerable.

The device had several other features, primarily to ensure safety. The system had a fail-safe mode such that any failure of the device caused the power wheelchair to stop and become inoperable. Movement of the power wheelchair could also be stopped by one of two emergency stop buttons located on the power wheelchair and underneath the computer. An additional all-stop control was enabled through the computer software. To better simulate the appearance of a future collision-avoidance power wheelchair, we included casings and mounts for the location of camera-based sensors on the power wheelchair.

A research technologist modified the power wheelchair. We completed risk analysis according to CAN/CSA (Canadian Standards Association)-ISO 14971:01 Medical devices-Application of risk management to medical devices [39]. A clinical engineer led risk management. 


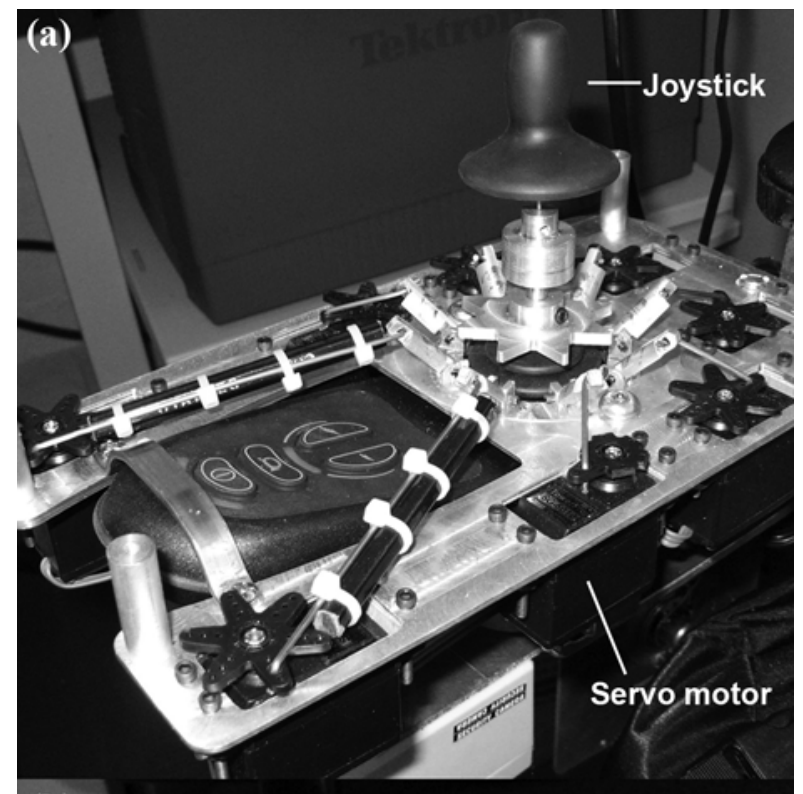

(b)

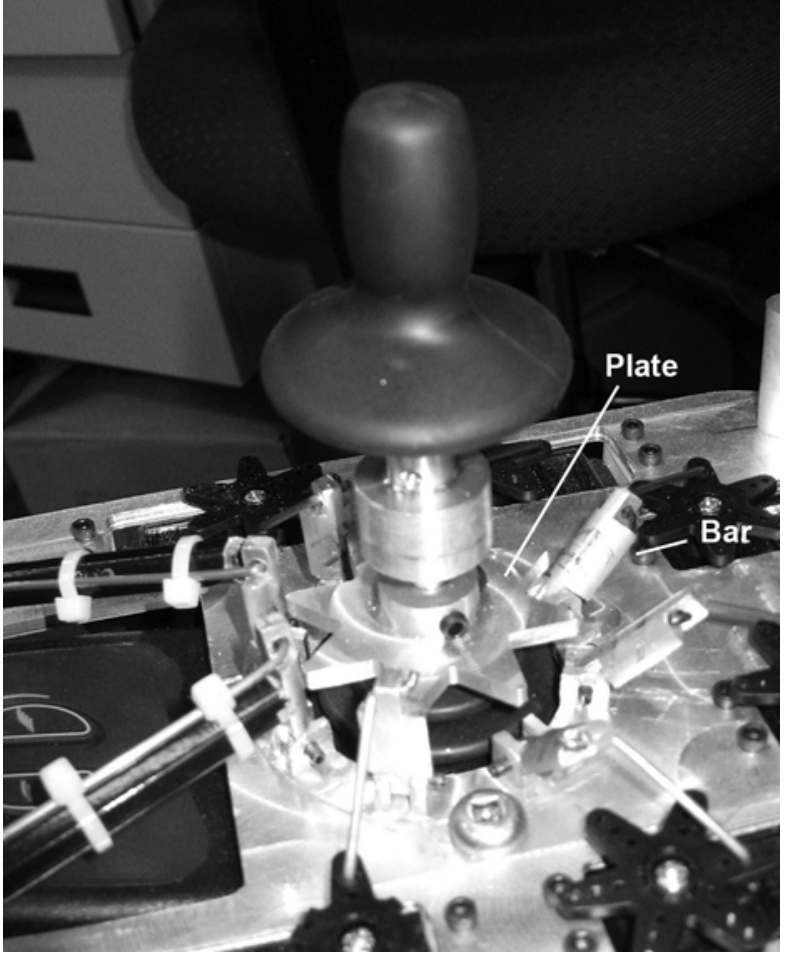

Figure 4.

Inside joystick interface showing haptic feedback mechanisms. When movement of power wheelchair stopped, directions of joystick movement (and power wheelchair movement) toward location of obstacle was blocked. (a) Eight radio-controlled servomotors mounted around base of joystick produced haptic feedback. (b) When activated, servomotor rotated a small plate that in turn moved a bar toward joystick. Joystick was attached to a plate that interfaced with bars. When a bar moved toward joystick, user could not move joystick in that direction, preventing movement of wheelchair in same direction.

\section{Subjects}

Residents were included in the study according to the following criteria: (1) had mild or moderate cognitive impairment screened using the Mini-Mental State Examination (MMSE) (score from 21-26/30 = mild, 11-20/30 = moderate) [40]), (2) spoke and understood English and responded to the interview questions and questionnaires, (3) consented or assented to participate in the study (with a substitute decision maker consenting, as necessary), and (4) used a manual wheelchair for primary mobility and could sit $>2 \mathrm{~h}$ at a time as confirmed by staff. Residents were excluded if they had a history of aggressive behavior leading to actual or risk of harm to others.

\section{Recruitment}

Residents were recruited based on staff recommendations. Staff asked residents and their substitute decision makers whether they were willing to speak with the primary investigator about the study. If they agreed, the investigator met with the resident and/or the substitute decision maker or spoke to the substitute decision maker on the telephone to review the study, consent procedures, and information and consent forms. For residents with substitute decision makers, we also sought assent from residents. The investigator explained the study to the resident using a simplified information and assent form. If willing, the resident signed the form. Willingness to participate was also confirmed on each study day. Residents were screened, and those who fit the inclusion and exclusion criteria were enrolled. We targeted five total residents for testing, with the number selected based on the recommendation that testing with five users can identify 80 percent of the usability issues [41]. Resolving issues identified from testing with five users allows product developers to move quickly to a new iteration of the design for subsequent testing.

\section{Study Procedures}

Before testing the device, the primary investigator assessed residents to understand their abilities better. The selection of assessments was based in part on the North Shore Health Power Mobility Assessment [42]. Assessments included standard tests for near acuity, distance vision, visual fields and scanning, and peripheral vision; visual perception using the Motor-Free Visual Perceptual Test-Third Edition [43]; and cognition using the MMSE (screening tool), Trail-Making Tests A and B, and the Clock Drawing Test. Behaviors such as distractibility, inattention, mental slowness, and the ability to follow directions were noted. The investigator completed a physical 
screen looking at sitting posture, upper-limb function, seating and joystick-controller requirements, transfers, and wheelchair mobility. Seating and positioning of the joystick controller were adjusted for comfort and function.

The investigator explained study procedures and the operation of the device to the resident. The resident was informed that the investigator was able to stop movement of the power wheelchair if an obstacle was nearby and deliver feedback using the computer attached to the wheelchair. The investigator was always present during DSs. Each session was approximately $1 \mathrm{~h}$ long and video-recorded by a research assistant. Each resident used the power wheelchair for 6 sessions over 6 different days. The first session was reserved for general orientation to the device, allowing residents to drive freely to become familiar with how the device operated and to assess whether changes in driving parameters (e.g., speed, turning speed, acceleration) or seating were needed. Subsequent sessions were dynamic and loosely structured with "warm-up” and "content” periods. During the warm-up, residents were able to drive wherever they wished and explore. The investigator then provided more instruction and suggested skills to practice, with routines differing with each session. The content was based on residents' choices for what they wished to do that day, selfidentified mobility goals (primarily self-care and leisure activities that they wished to perform as part of their day), and the driving skills and tasks outlined in the PIDA (additional information follows). The pace of the training sessions and driving activities was graded according to the resident's tolerance and performance. The investigator scored the PIDA based on the residents' last performance of each task. Field notes were made of observations and resident comments offered during driving sessions. Notes were related to residents' self-identified mobility goals and efficiency and satisfaction with the device.

The investigator completed interviews and questionnaires after residents completed all six driving sessions. Interviews were built primarily around standard evaluation protocols that will be described later. Residents were asked questions about what they thought about the power wheelchair and user interface, how the device worked for them and whether they understand how the device worked (what helped or hindered their understanding), the feedback that was provided when obstacles were nearby, the usefulness of the device, and suggestions that they might have to improve the device. Information related to the questionnaires is provided in the following paragraphs. Interviews and questionnaire responses were audio-recorded.

\section{Power-Mobility Indoor Driving Assessment}

The PIDA was developed to be a valid and reliable instrument to assess the power wheelchair or scooter mobility of long-term-care home residents [34,44]. The PIDA was also intended to evaluate change over time after a mobility intervention. Items to be performed related to skilled driving (turning right, left, and $180^{\circ}$; driving backward; manipulating in congested areas; maneuvering; and responding to unexpected obstacles) and mobility around the bedroom, bathroom, doors, elevators, parking, and ramps. Only items relevant to the resident's environment or daily requirements were scored. Items were scored on a performance scale from 1 to 4 , with 1 being unable to complete the task and 4 being completely independent. We calculated total percentage score by summing all the scored items and dividing by four times the number of items scored. The PIDA has been used clinically and has been described in a study that examined two driving training protocols for older adults living in institutions [45].

\section{NASA-Task Load Index}

The NASA-TLX is a widely used measure that evaluates workload in six subscales: Mental Demand, Physical Demand, Temporal Demand, Performance, Effort, and Frustration [35]. Ratings for the subscales were made from 0 to 20 and converted to a rating out of 100 , with lower scores meaning "low" (e.g., for mental demand) or "good" (e.g., for performance). The resident assigned weights based on 15 pairwise comparisons of the relevance of the task on workload subscales. An overall workload score from 0 to 100 was calculated based on the subjective weights given. The NASA-TLX has been used in many studies investigating the perceived workload of automobile drivers, including older adult drivers, under various driving conditions [46-48] and used in a study evaluating shared user and autonomous driving control of an intelligent wheelchair with users without disabilities [49].

\section{Quebec User Evaluation of Satisfaction with Assistive Technology 2.0}

We used the QUEST to assess user satisfaction with devices and services using 12 items on a 5-point scale [36]. We calculated the overall QUEST score by averaging the results for all items scored. Details of the psychometric properties are found in the QUEST manual [50]. The Danish version of the QUEST has been used in a study looking at older adults who use power wheelchairs [51]. The QUEST has also been used in studies examining 
seating and positioning device interventions in older adults in nursing homes [52] and community-based users of mobility devices [51].

\section{Psychosocial Impact of Assistive Devices Scale 3.0}

The PIADS is a questionnaire consisting of 26 items that measures impact in three subscales: Competence, Adaptability, and Self-Esteem [37]. The scale is composed of items that are elemental to quality of life. The user rates items on a 7-point scale, ranging from -3 (maximum negative impact) to +3 (maximum positive impact). The PIADS was designed to be used either before a user received the device to assess his or her expectation of the device or after a user received the device [37]. The instrument has been used with older adult wheelchair users [53] and power wheelchair users [54].

\section{Data Analysis}

The number of self-identified mobility goals achieved and results from the predriving assessments, PIDA, NASATLX, QUEST, and PIADS were tabulated. Notes made during review of the video data for each DS supplemented field notes made during the study. For each resident, data were labeled according to the DS number (e.g., DS.1) or labeled as "Interview." All interviews were transcribed verbatim, with identifying information removed. The primary investigator transcribed most interviews, with three trained research assistants transcribing the remaining 25 percent. Then the investigator checked the 25 percent. Data from all sources were summarized and organized under the domains of effectiveness, efficiency, and user satisfaction. Thematic analysis techniques were used with the qualitative data pertaining to user satisfaction.

\section{RESULTS}

Five residents participated from two sites: George and Mark from one site and Jim, Lilian, and Gerry from a second site. For anonymity, we have used pseudonyms. Another resident was enrolled but dropped out during assessment because he did not want to complete the predriving assessments. Table 1 describes the residents.

Results from the five residents supported the hypotheses related to usability. Residents were accepting of the device consisting of the simulated collision-avoidance power wheelchair and multimodal user interface. Each domain of the usability evaluation is discussed in the following paragraphs.

\section{Effectiveness}

Effectiveness was defined as "being able to complete a task" [33]. Overall, the device was considered effective in enabling the two residents who had indoor mobility goals to complete their self-identified mobility goals and effective by helping residents to achieve most of the basic driving tasks outlined in the PIDA.

\section{Achievement of Mobility Goals}

All residents, except Gerry, verbalized mobility goals. Achievement of self-identified indoor mobility goals of residents using the device was high. Outdoor mobility was not explored because most residents required further practice to achieve indoor driving proficiency before driving outdoors. Interestingly, George and Mark only identified goals outside the facility. Lilian and Jim expressed goals that were both outside and inside the long-term-care home. Table 2 summarizes these findings.

\section{Driving Performance on PIDA}

The basic driving tasks, under the Skilled Driving section of the PIDA, applied to all residents. The relevance of other sections of the PIDA depended on the residents' daily routines. Scoring for the PIDA was completed over several sessions and based on the last performance of each applicable task that was practiced. A summary of the performance on the PIDA for each resident is provided in Table 3. Mark completed the applicable driving tasks within two sessions. The other four residents, George, Jim, Lilian, and Gerry, performed the applicable tasks in three to four sessions. At the end of the six DSs, most residents performed the basic driving tasks under the Skilled Driving section, with passing scores between 3 = "Completes task hesitantly, requires several tries, requires speed restriction, and/or bumps wall, objects, etc. lightly (without causing harm)" and $4=$ "Optimal performance: able to perform task in one attempt smoothly and safely.” Of note, two residents, George and Jim, required more repetitions of the instructions or prompting assistance from the investigator for the driving backward task, and Jim additionally for the maneuverability item and hence scored 1 = "Unable to complete task" on these items. The more complex driving tasks under the Bedroom, Bathroom, Elevators, and Parking sections did not apply to all residents, but for some, these tasks necessitated more practice than was possible in the six DSs. 
Table 1.

Descriptive summary of five study residents.

\begin{tabular}{|c|c|c|c|}
\hline $\begin{array}{l}\text { Resident (Age at } \\
\text { Time of Study) }\end{array}$ & $\begin{array}{c}\text { MMSE } \\
\text { Score }\end{array}$ & Primary Diagnoses & Manual Wheelchair Mobility \\
\hline George (68) & $20 / 30$ & $\begin{array}{l}\text { Degenerative disorder of nervous system (not } \\
\text { specified) for } 25 \text { yr, left basal ganglia cavern- } \\
\text { oma, right frontal gliosis. } \\
\text { Spinal stenosis, degenerative disc disease. } \\
\text { Stroke } 10 \text { yr ago, multi-infarct dementia. } \\
\text { Hypertension. } \\
\text { Chronic obstructive pulmonary disease. } \\
\text { Diabetes type } 2 \text {. }\end{array}$ & $\begin{array}{l}\text { Wheels slowly with legs, going backward often, } \\
\text { pulls along handrails in hallway frequently. } \\
\text { Mobile in room \& common areas. }\end{array}$ \\
\hline Mark (63) & $24 / 30$ & $\begin{array}{l}\text { Acquired brain injury } 1 \text { yr ago, intracranial } \\
\text { (subarachnoid) hemorrhage. } \\
\text { Depression. } \\
\text { Cardiomyopathy, hypertension, coronary artery } \\
\text { disease, ischemic heart disease. } \\
\text { Alcohol abuse. }\end{array}$ & $\begin{array}{l}\text { Wheels with legs \& sometimes arms, pulls } \\
\text { along handrails in hallway frequently. } \\
\text { Mobile in room \& common areas. }\end{array}$ \\
\hline $\operatorname{Jim}(76)$ & $24 / 30$ & $\begin{array}{l}\text { Parkinson disease. } \\
\text { Multi-infarct dementia. } \\
\text { Right hip fracture } 1 \text { yr ago with open reduction } \\
\text { internal fixation. } \\
\text { Depressive episodes. }\end{array}$ & $\begin{array}{l}\text { Wheels minimally with arms \& legs in room, } \\
\text { says wheelchair is heavy. } \\
\text { Wheeled by others outside room. }\end{array}$ \\
\hline Lilian (86) & $24 / 30$ & $\begin{array}{l}\text { Stroke } 2 \text { yr ago, intracerebral hemorrhage, right } \\
\text { hemiplegia. } \\
\text { Left lower-leg amputation. } \\
\text { Acute \& chronic renal failure. } \\
\text { Right malleolus ulcer. }\end{array}$ & $\begin{array}{l}\text { Can only turn left (only left arm has functional } \\
\text { mobility) in room. } \\
\text { Wheeled by others outside room. }\end{array}$ \\
\hline Gerry (74) & $13 / 30$ & $\begin{array}{l}\text { Left middle cerebral artery stroke, right hemiplegia, } \\
\text { hypertension. } \\
\text { Depression. }\end{array}$ & $\begin{array}{l}\text { Wheels slowly with left arm \& leg for short } \\
\text { distances inside room or lounge area. } \\
\text { Wheeled by others for longer distances. }\end{array}$ \\
\hline
\end{tabular}

Residents scored $>3$ or 1 under these sections. Negotiating the elevators was found to be the most challenging task, and residents scored 1 in two or more components of the task (“entering elevator," "spacing in elevator," or “exiting elevator”). Mark, who had a lot of previous driving experience, mastered the majority of tasks, except entering and exiting the elevator. The time that residents required to complete the elevator task may be nonfunctional, particularly if others were waiting to use the elevators. More time was necessary because of the device's slow speed and the residents' need to renegotiate when other people or obstacles were nearby. Notably, use of the device with the simulated collision-avoidance feature effectively eliminated the likelihood of achieving a score of $2=$ "Bumps objects or people in a way that causes or could cause harm.” Therefore, the collision-avoidance feature increased driving safety and helped residents complete these driving tasks, guided by the feedback when obstacles were encountered.

\section{Efficiency}

Efficiency was defined as "the amount of effort required to complete the task" [33]. We used two scales to evaluate efficiency. The first scale used the PIDA to assess whether residents were able to operate the wheelchair and user interface within six $1 \mathrm{~h}$ DSs. The second scale used the NASA-TLX to measure self-reported workload. 
Table 2.

Self-identified mobility goals and goal achievement of five study residents.

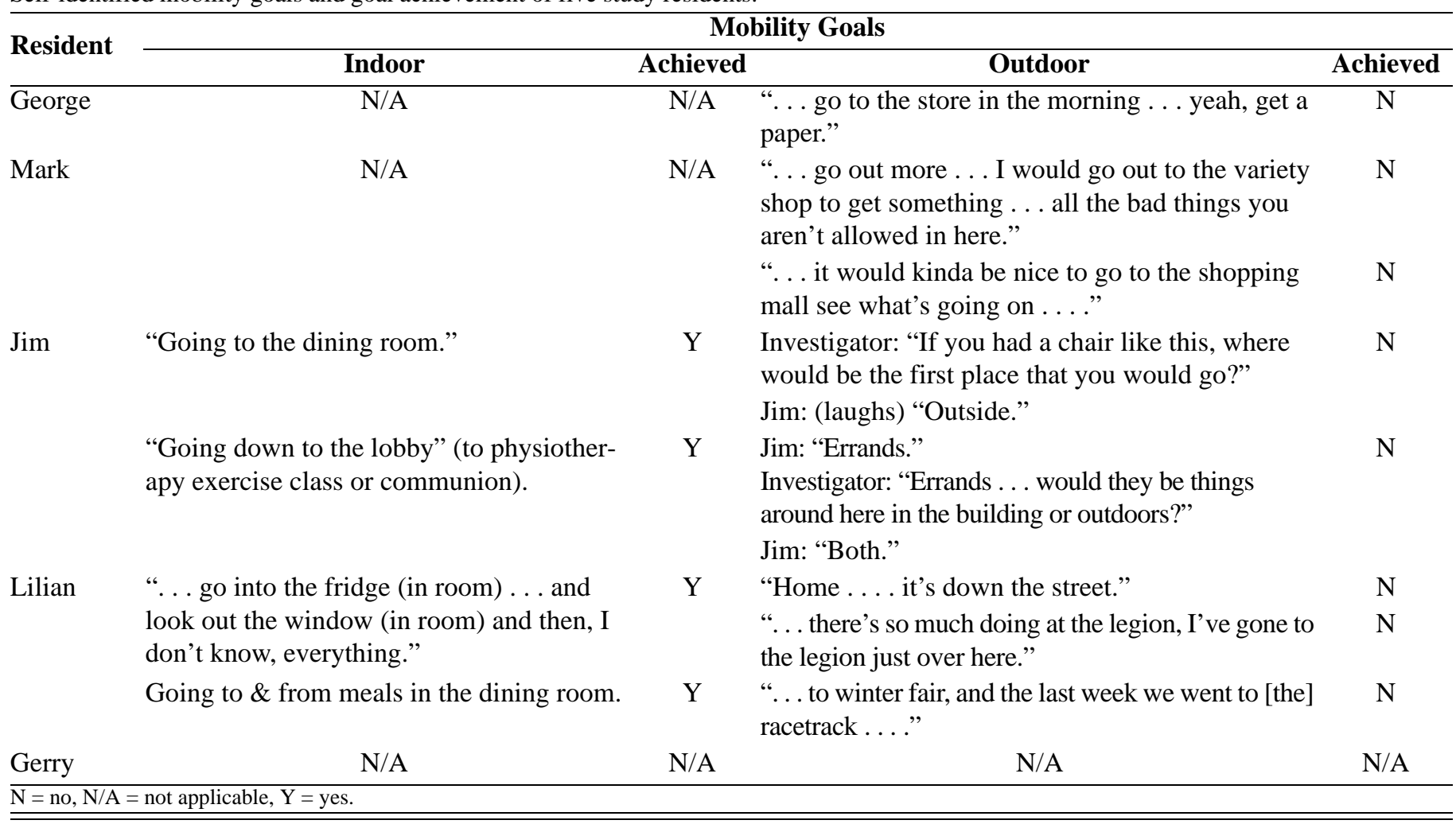

Table 3.

Summary of performance on Power-Mobility Indoor Driving Assessment of five study residents.

\begin{tabular}{lcc}
\hline Resident & $\begin{array}{c}\text { Applicable Items } \\
\text { Scored (No.) }\end{array}$ & $\begin{array}{c}\text { Total Score } \\
(\mathbf{\%})^{\dagger}\end{array}$ \\
\hline George & 25 & 76 \\
Mark & 27 & 91 \\
Jim & 20 & 64 \\
Lilian & 22 & 66 \\
Gerry & 15 & 88 \\
${ }^{*}$ Maximum possible: 30. & \\
${ }^{\dagger}$ Total score (\%) $=[$ sum of scores for each applicable item/(4 $\times$ number of \\
applicable items)] $\times 100$.
\end{tabular}

\section{Time to Learn Operation}

Residents were able to operate the power wheelchair and user interface within six $1 \mathrm{~h}$ DSs. That is, they performed a majority of the basic skills to drive the device. Additional practice was necessary for all residents, except Mark, to achieve proficiency.

Varying levels of performance were achieved at the end of the six DSs, even though the basic skills were achieved. The pace and activities of the sessions were dictated by the activity tolerance of each resident, their performance with each successively more difficult task, and the speed at which they completed tasks. Mark, who had the most experience with driving and navigating many types of vehicles, was able to use the device within three DSs and satisfactorily completed the majority of tasks on the PIDA. The other residents required more practice with the complex tasks, which were not achievable within six sessions. Jim and Gerry were limited in their activity tolerance; hence, the pace was slower than with Mark and George. Lilian had limited experience operating a vehicle, had not driven a car before, and was allocated more time to accustom herself to navigating with the joystick.

\section{Workload}

Table 4 summarizes the results of the NASA-TLX. Most residents reported low levels of overall workload, suggesting that the personal cost for operating the device was low. Gerry could not respond to the weighting section for the assessment. Likely because of his language difficulties, he was not able to select between the two words 
Table 4.

Summary of NASA-Task Load Index.

\begin{tabular}{|c|c|c|c|c|c|}
\hline NASA-Task Load Index & George & Mark & Jim & Lilian & Gerry* $^{*}$ \\
\hline Overall Workload (out of 100) & 15.3 & 14.7 & 39.3 & 27 & Incomplete \\
\hline \multicolumn{6}{|l|}{ Mental Demand } \\
\hline $\mathrm{W}$ & 1 & 2 & 4 & 3 & - \\
\hline $\mathrm{R}$ & 25 & 15 & 35 & 20 & 15 \\
\hline \multicolumn{6}{|l|}{ Physical Demand } \\
\hline $\mathrm{W}$ & 3 & 0 & 1 & 2 & - \\
\hline $\mathrm{R}$ & 35 & 15 & 65 & 15 & 15 \\
\hline \multicolumn{6}{|l|}{ Temporal Demand } \\
\hline $\mathrm{W}$ & 2 & 3 & 3 & 2 & - \\
\hline $\mathrm{R}$ & 15 & 15 & 35 & 10 & 10 \\
\hline \multicolumn{6}{|l|}{ Performance } \\
\hline $\mathrm{W}$ & 5 & 3 & 3 & 5 & - \\
\hline $\mathrm{R}$ & 10 & 25 & 30 & 50 & 5 \\
\hline \multicolumn{6}{|l|}{ Effort } \\
\hline $\mathrm{W}$ & 4 & 2 & 3 & 3 & - \\
\hline $\mathrm{R}$ & 5 & 10 & 55 & 15 & 10 \\
\hline \multicolumn{6}{|l|}{ Frustration } \\
\hline W & 0 & 5 & 1 & 0 & - \\
\hline $\mathrm{R}$ & 10 & 10 & 25 & 10 & 5 \\
\hline \multicolumn{6}{|c|}{$\begin{array}{l}\text { Note: Maximum weight }(\mathrm{W})=15 \text { and maximum rating }(\mathrm{R})=100 \text { (lower scores } \\
\text { indicating "low" or "good"). } \\
\text { "Did not select weights. }\end{array}$} \\
\hline
\end{tabular}

when they were presented on a card. However, even when the two words were presented verbally and explained, he did not select one. Nevertheless, he was able to complete the rating scales that indicated that workload on the six individual subscales was low.

\section{User Satisfaction}

Evaluation was based on comments offered during DSs and interviews and from the results of two questionnaires, the QUEST and PIADS. Overall, residents were very satisfied with the device. Refer to Table 5 for a summary of device acceptance and satisfaction with the device and individual modes of feedback. Aspects of user satisfaction found in the analysis of resident comments and interviews were grouped into four categories: (1) overall device, (2) multimodal feedback interface, (3) ease of use, and (4) speed.

\section{Overall Device}

Residents reported the simulated collision-avoidance power wheelchair and the user interface with different modes of feedback to be useful. Except Mark, the residents were interested in using a device like the one they tested.
Table 5.

Summary of device acceptance and satisfaction with device and multimodal feedback.

\begin{tabular}{|c|c|c|c|c|c|}
\hline \multirow{2}{*}{ Resident } & \multirow{2}{*}{$\begin{array}{l}\text { “Liked” and } \\
\text { “Would Use” } \\
\text { Device if } \\
\text { Available }\end{array}$} & \multirow{2}{*}{$\begin{array}{c}\text { Satisfied } \\
\text { with } \\
\text { Device }\end{array}$} & \multicolumn{3}{|c|}{$\begin{array}{l}\text { Satisfied with Feedback for } \\
\text { Moving Away from Obstacles }\end{array}$} \\
\hline & & & Auditory & Visual & Haptic \\
\hline George & $\mathrm{Y}$ & $\bar{Y}$ & $\mathrm{Y}$ & $\bar{Y}$ & $\bar{Y}$ \\
\hline Mark & $\mathrm{N}$ & Y & $\mathrm{Y}$ & $\mathrm{N}$ & $\mathrm{N}$ \\
\hline Jim & $\mathrm{Y}$ & Y & $\mathrm{Y}$ & $\begin{array}{l}\text { Response } \\
\text { unclear }\end{array}$ & $\mathrm{Y}$ \\
\hline Lilian & $\mathrm{Y}$ & $\mathrm{Y}$ & $\mathrm{Y}$ & $\mathrm{Y}$ & $\begin{array}{l}\text { Response } \\
\text { unclear }\end{array}$ \\
\hline Gerry & $\mathrm{Y}$ & Y & $\mathrm{Y}$ & Y & $\mathrm{Y}$ \\
\hline
\end{tabular}

Jim even asked whether such a power wheelchair would be available for him to rent. Related to the collision-avoidance feature of the power wheelchair, they recognized that the device not only helped them be more mobile and independent but also prevented accidents. George said, “. . . it stops before it hits it or have an accident ... I think it's a great idea” (DS.5). Jim said that it was a lot easier moving the power wheelchair compared with his manual one, in which he struggled to move even a short distance inside his room. The added safety and assistance features were beneficial, as he said, "I got a lot of help with ... the driving . . . . I prefer to have the computer's help" (DS.4). Lilian could only use her left arm to move her manual wheelchair (in circles) and focused on the independence that a power wheelchair offered. At the end of the study, she said, "I can get around better . . . you don't always have to wait for somebody . . . you feel obligated to somebody be able to help ya, and this way you do things yourself" (Interview). Like George, she supported the idea of the collision-avoidance feature saying, "It's good because it stops before you are in trouble . . . ." (Interview). Gerry liked the collision-avoidance feature as well, since he was surprised but appreciative when movement of the power wheelchair stopped and he was prompted to navigate around an obstacle that he had not noticed. Mark did not feel he personally needed a power wheelchair or the extra features that the device offered but supported it for other people, "For the right person, it's a great idea and device ... . . I know there are a number of people in here who it would just be absolutely wonderful for because they really struggle ....” (Interview). 


\section{Multimodal Feedback Interface}

Residents thought that the added assistance to move away from obstacles once the power wheelchair stopped was a good idea and generally felt that the different feedback modalities (auditory, visual, and haptic) were helpful. However, nuances were identified with each of the modalities that warranted mention.

Auditory. All residents perceived auditory feedback to be useful throughout the DSs. Residents said during the DSs and final interviews that the recorded messages were clear and easy to understand. They also did not have concerns with the tone of voice, nor a preference for a woman's or man's voice. Nevertheless, Mark jokingly commented that a woman's voice was a good choice: “. . . obviously they know the way to get things done-put it in a lady's voice, right?” (DS.3). Residents reported that they followed the audio-recorded directions given to them. During the follow-up interview, George concluded, "she [auditory prompt] gave good advice.” Lilian found that the prompts gave the correct directions and said that she did not catch situations when the prompts were unsuitable. Interestingly, George and Mark noted astutely that the audio prompts did not give what they felt were appropriate directions in a few situations while navigating within small spaces and while multiple obstacles were nearby. The simple one-step prompts did not communicate the number and proximity of all surrounding obstacles, and multiple small maneuvers in different directions were often necessary to negotiate around them. Thus in one instance (DS.4), George turned away from an obstacle and the prompt delivered was, "All Clear," but because he was in a tight space, he then became close to the wall on the left side. He laughed and noted, "It's telling 'All Clear' and I'm hitting the wall.” In another case with Mark, multiple chairs and tables were close during a parking task in the dining room and Mark noted, "It's telling me to turn left, but if I turn, I'm going to turn my back into the table" (DS.3). In these cases, residents used their observation skills and judgment before automatically following the directions. Lilian, during the final interview, suggested that dependence on the technology was possible, but she did not want to depend on the audio prompts and automatically follow directions without thinking.

Visual. The visual prompts or indicator lights were perceived to be useful during certain circumstances. Most of the residents, except Jim who was not consistent with his responses regarding the lights, understood that the lights indicated the directions of allowed movement. Residents, such as Lilian, tended to look down at the joystick in the early stages of learning to drive the power wheelchair. In response to whether he used the indicator lights, Mark, the experienced driver, acknowledged this behavior as, "Not a whole lot other than when you are first starting out you want to know; the lights at least let you know because they show .....” (DS.3). George and Gerry looked at the indicator lights when movement stopped. Gerry reported during the final DS that he thought the indicator lights were useful but not while driving. When he stopped, he said he would look down, but for "just seconds." Interestingly, Lilian articulated that she used the indicator lights combined with the auditory prompts. In the final interview discussing what helped her understand how the power wheelchair worked, she said, "All the numbers [lights] all around it [joystick], and she [audio prompt] says forward and to the left, right, and they light up and you go from there." She also suggested that the lights were useful as backup to show which directions to go after the auditory prompts were presented. Mark said that the indicator lights were the least useful feedback strategy for him (Interview). He said in an early DS (DS.3) that operating a joystick was more based on "feel," alluding to the importance of a more tactile feedback strategy. During the final interview, he said that most joysticks do not have lights around them and that operating a joystick is mostly based on "instinct or response of the machine.”

Haptic. Similar to the visual feedback responses, the haptic feedback responses were mostly positive. George, Jim, and Gerry felt that the haptic feedback, described to the residents as the directions that were blocked because of an obstacle, was very useful. Whether Lilian found the haptic feedback to be useful was unclear. When asked about it during the final interview, she did not seem to recall that it was a special feature of the device she tested. During the DS, however, she appeared to adapt readily to using the device and understood how it operated. Mark thought the blocked directions were too restricting, although he understood that modifications to the device were made to improve safety. He suggested that a warning at a certain proximity to obstacles would be more beneficial. A warning prompt would give him more of an opportunity to redirect his course and that he would have more choice with what he could do (DS.3). A warning prompt would likely benefit Jim as well, who felt the haptic feedback was useful but "unexpected" when it was delivered (DS.2). 


\section{Ease of Use}

Residents had varying levels of prior experience with operating wheeled devices and joystick controllers, ranging from no experience driving a car or power mobility device (Lilian) to experience driving various vehicles, including cars and trucks, and joystick-controlled construction equipment such as skid steer loaders (Mark). All residents indicated at the end of the sessions that they easily understood how to drive the power wheelchair and understood the feedback. This suggested that the device was intuitive to use and easy to learn how to operate. Lilian who had the least experience, initially thought that driving was, "very nice . . . if you're used to it," indicating some hesitation about her comfort level (DS.1). By the sixth DS, she said driving with the joystick controller was effortless or, "Just sitting here and pressing the button [joystick]." During the last DS, Gerry reported that when initially using the joystick, he felt "clumsy and then you learn" and that the factor that helped him to understand how it worked was the investigator giving him instructions (DS.6). Mark indicated that his previous experience helped him to operate the joystick controller easily and proficiently to drive the power wheelchair. He reported, 'I'm sure that anything like this would be second nature after a very brief time" and that it was "very simple to operate the machine” (DS.4).

\section{Speed}

One source of dissatisfaction with the device was the slow driving speed. By the last session, all residents except Gerry were set at the maximum speed of $1.8 \mathrm{~km} / \mathrm{h}$. Gerry, because of personal choice, drove at a maximum of $1.6 \mathrm{~km} / \mathrm{h}$. George, Jim, and Lilian's only recommendation to improve the device was to make it go faster. George identified as early as the third DS that he wanted it to go faster. When asked about a desirable driving speed for an environment with many people walking with walkers or others using wheelchairs he suggested "about 10 miles an hour [16 km/h].” During the initial sessions, Jim felt the driving speed was slow, but tolerable. After completing the last DS, he asked whether the device would eventually go faster, suggesting 50 percent faster. He also stated that while driving, especially "proceeding down the corridor . . . the chair's speed is . . . a nuisance" (Interview). The slow driving speed significantly concerned Mark from the time he started testing the device. He felt the slow speed was not functional for him because he could go faster in his manual wheelchair. He identified that the speed restricted the possibility of getting on and off the elevators independently because the timed doors were not designed for the slow speed of the device. The speed that seemed reasonable to Mark was the walking pace of other residents, because he said, "I know we are in trouble when this older gentleman and this older lady with her walker pass me [says jokingly]" (DS.1). He reiterated during another session (DS.2) that he wanted only to go at a speed at which he would normally walk. Gerry, who took things slowly, did not feel that he wished it to go faster in the initial sessions. He suggested that once his driving improved, then he could speed up. During the third DS, he indicated that he wanted to have the option of the speed going faster and slower. This suggested that he preferred to have good control of driving and that correct speed modulation was important for him. In the follow-up interview, he said that his driving speed depended on the situation, so maximum speed was not a big concern for him.

\section{Measure of User Satisfaction}

User satisfaction was confirmed by results of the QUEST. Table 6 shows the summary scores (total and subscale scores) for each resident. Gerry felt that he needed more experience with using the device and more DSs to complete this assessment. Device subscale scores were high, ranging from 3.75 to 5.00 out of a maximum of 5.00, which indicated a range of "satisfied" to "very satisfied."

\section{Measure of Psychosocial Impact on Well-Being}

The PIADS examined the impact of assistive device use on subjective well-being. Table 7 summarizes scores

Table 6.

Summary of Quebec User Evaluation of Satisfaction with Assistive Technology 2.0.

\begin{tabular}{lccc}
\hline \multirow{2}{*}{ Resident } & \multirow{2}{*}{$\begin{array}{c}\text { Total } \\
\text { Score }\end{array}$} & \multicolumn{2}{c}{ Subscale Score } \\
\cline { 3 - 4 } & 4.89 & Device & Services* \\
\hline George & 3.91 & 3.00 & 4.67 \\
Mark & 4.00 & 3.88 & 4.33 \\
Jim & 4.36 & 4.25 & 4.33 \\
Lilian & Incomplete & 3.75 (uncertain & Incomplete \\
Gerry $^{\dagger}$ & & of validity) & \\
& & & \\
\hline
\end{tabular}

Note: Maximum for Total and Subscale Scores $=5: 3=$ more or less satisfied, $4=$ quite satisfied, and 5 = very satisfied.

*Item 12: "Follow-Up Services" omitted because it was not applicable.

${ }^{\dagger}$ Did not feel many of questions were valid because he did not use device long enough to evaluate. 
Table 7.

Summary of Psychosocial Impact of Assistive Devices Scale.

\begin{tabular}{lccc}
\hline \multirow{2}{*}{ Resident } & \multicolumn{3}{c}{ Subscale Score } \\
\cline { 2 - 4 } & Competence & Adaptability & Self-Esteem \\
\hline George & 0.50 & 0.33 & 0.38 \\
Mark & 0.75 & 1.12 & 0.38 \\
Jim & 2.25 & 2.25 & 1.88 \\
Lilian & 2.17 & 2.50 & 2.13 \\
Gerry & 0.17 & 1.67 & 0 \\
Score range from -3 to 3, $0=$ not any more or less, 1 or 2 = somewhat more, \\
3= very much more. \\
\hline
\end{tabular}

of each of the three subscales of the PIADS. Use of the device did not negatively affect well-being; that is, no scores were below zero. However, for George, Mark, and Gerry, using the device had little impact on well-being. For Jim and Lilian, use of the device was reported to contribute to positive well-being. Subscale scores ranged from 1.88 to 2.25 for Jim, indicating "somewhat more" to "very much more" and 2.13 to 2.50 for Lilian, suggesting "very much more."

\section{DISCUSSION}

Little work has been reported on interfaces for modified power wheelchairs for older adult users with cognitive impairments and the technology features to promote power mobility use. Hence, little previous research evidence exists with which to compare our findings. Results from this usability study have important implications for the development of advanced power wheelchair technology. Results indicated that a device that includes a power wheelchair with collision-avoidance capability and auditory, visual, and haptic feedback to aid navigation might be effective, efficient, and satisfying for residents with mild or moderate cognitive impairments.

Appropriate feedback or prompting for user actions is essential to improve driving performance, minimize confusion and frustration of users, and enable users to maintain as much control of their mobility as possible. The absence of such assistance was found to be a usability problem, resulting in decreased device effectiveness and user dissatisfaction and contributing to device nonacceptance in a previous study that evaluated an anticollision power wheelchair [17]. Guided by findings from this previous study, we developed an improved user interface and tested it together with a simulated collision-avoidance power wheelchair.

The modes of feedback were not tested separately for several reasons. We hypothesized that the multimodal approach was the most appropriate and required evaluation with the auditory, visual, and haptic feedback delivered together. This approach aimed to accommodate for declines in sensory and perceptual system functioning often seen with older adult long-term-care home residents and to offer redundancy [55] to increase the possibility of correct responses and thus improve driving performance. Use of multisensory assistance has also enhanced the performance of many complicated motor actions by compensating for unreliable information or one sensory modality already engaged [31].

We used a simulation because we did not expect that a fully reliable noncontact sensor-based collision-avoidance system, sensitive and robust to variable environmental conditions and safe for testing in the long-term-care environment, would be developed for several years. Furthermore, before proceeding with the design of a more advanced power wheelchair, we needed to understand this user population and their technology requirements. One of the main benefits of testing with a simulated system applied to a conventional power wheelchair is that it removes concerns about the appearance of a prototype collision-avoidance power wheelchair, lacking the aesthetics of a manufactured product that may affect the user's perception of the device. Testing with a simulated system addressed findings from the previous study in which the appearance of the prototype confounded perceptions of the device's capabilities [56].

\section{Usability Evaluation}

Our findings generally supported the hypotheses pertaining to effectiveness, efficiency, and user satisfaction, and the device is considered to have good usability for residents with mild or moderate cognitive impairment when used in the institutional care context. As for the collision-avoidance feature of the power wheelchair, residents recognized that the device assisted them to be more mobile and independent but also prevented accidents.

A notable finding was that residents found using the device to be low in workload and frustration. A summed overall score of 40 on the 100-point scale has been previously used as a criterion for high workload [57]. Only one resident, Jim, was close to the threshold. Some researchers have considered completion of the weights component of 
the NASA-TLX to be unnecessary, because the correlation between weighted and unweighted workload scores was found to be +0.94 [58]. In the case of Gerry, who did not respond to the questions on weights, we conclude that based on his workload ratings, overall workload was low. Residents with multiple chronic conditions living in longterm-care homes often have low tolerance for activities. Power wheelchair use may help conserve energy and decrease physical workload for self-mobility [59-60], but mental workload must also be considered. An increase in mental workload because of the need for increased alertness is a possibility with power wheelchair use with this user population [56]. Additionally, in a study that compared manual, autonomous, and semiautonomous driving modes in an intelligent power wheelchair, users (aged 18 years and older) indicated that the autonomous driving mode required the least effort but was frustrating because they did not experience control over their mobility [49]. As expected, users felt the most control using the power wheelchair in the manual mode, but this required the greatest amount of effort. Users preferred the semiautonomous mode as an intermediary between using excessive effort and feeling frustrated related to lack of control. Users in this current study who tested the simulated collision-avoidance power wheelchair and multimodal interface more directly controlled the movement of the power wheelchair, as opposed to the semiautonomous driving mode described by Parikh et al. [49]. Users who used the multimodal interface experienced only a momentary loss of control when an obstacle was nearby and power wheelchair movement stopped. Overall workload considerations are extremely important because use of technology is beneficial and acceptable only if the cost of using the technology for physical and mental input is considered low [61].

User satisfaction was generally high for the device. Indeed, four of the five users felt they would like a power mobility device like the one they tested. This was in contrast to the device tested by Wang et al. [17], in which acceptance of the device was low because of the poor interface usability, appearance, decreased functionality, and slow driving speed. Not surprisingly, the speed of the device evaluated in this study was found to be an area of dissatisfaction. Despite the somewhat higher speed of approximately 40 percent of an average walking pace for the device tested in this study compared with the 20 percent in Wang et al. [17], driving speed was still a problem. Slow speed in a power wheelchair has functional and social implications for the user [56]. Nevertheless, speed needs to be catered to the resident's needs and abilities and to the driving environment. As indicated by Jim and Gerry, speed depends on the location of driving; for example, in a straight corridor with few people, a faster speed may be appropriate. Researchers may need to investigate different modes of driving to accommodate driving in large spaces that are relatively free of obstacles and in smaller spaces where contact with obstacles may be more likely. Ultimately, the maximum speed will be determined by the capability of the collision-avoidance technology to detect both static and dynamic obstacles and stop or turn the power wheelchair in time. The technology may need to also track and predict movement paths of dynamic obstacles, such as ambulatory residents whose behavior may be erratic, causing them to unexpectedly and suddenly step into the path of the power wheelchair.

The residents' use of elevators is an important concern identified. With the device, the residents had difficulty entering and exiting the elevator before the doors closed. More time was necessary because of the device's slow speed and the residents' need to negotiate around people or other obstacles. Notably, slow driving speed in power wheelchairs is not specific to future collision-avoidance power wheelchairs because driving speed in the longterm-care home setting is often reduced for safety reasons, and the rapid closing of elevator doors is an existing issue. Various possibilities may exist to address the issue of elevator use. One may simply be to lengthen the door opening times for elevators in long-term-care settings. A signal may be directed at the elevators (either automatically as the power wheelchair approaches or by way of a remote control) to indicate that a power wheelchair with a slower operating speed is approaching and the elevator doors can remain open longer. As technology improves, future collision-avoidance power wheelchairs may have the driving speed to accommodate elevator use; however, maximum driving speed may still be restricted as just described. Future collision-avoidance power wheelchairs may include semiautonomous modes for situations like these in which technology may help increase speed and accuracy. Of course, given the need for users to maintain control of driving and their degree of possible frustration, use of semiautonomous modes will need further exploration.

\section{Multimodal Feedback}

We discovered several interesting points raised from the residents' responses to the multimodal feedback. Based on their responses to the feedback, we found that different 
modes of feedback might be more useful at different times during driving. All residents reported that the auditory prompts were helpful. Understandably, this finding is because audition is often used in alerting systems to readily catch a user's attention [28]. Once movement of the power wheelchair stopped and the auditory prompts alerted the residents, most residents seemed to look down to the indicator lights for additional guidance. Unimodal visual feedback may not be useful since during driving and navigation activities, the visual system is often already attending to multiple sources of stimuli in the environment. Indeed, skilled driving requires that the driver look up and ahead to drive straight, scan the environment, and anticipate obstacles. Hence, the placement of the visual prompts in the device tested in this study was likely appropriate because it was not in the front field of view to detract from the optimal viewing of the environment.

Also, certain modes of feedback seem to be more or less dominant for the driver to progress from inexperienced to experienced. The residents, including Mark the most experienced driver, said they would look down at the joystick and indicator lights when they were first starting to drive. Once they were more familiar with operating the device, they looked up to the environment in front of them. At a more skilled level, Mark found that he based driving and navigation on "feel." These observations suggest that haptic information in general may be useful with skilled motor performance and that visual input is primarily engaged when a user is first learning to manipulate the joystick.

The haptic feedback used in this study is powerful because it ensures the correct directions of movement if residents try to direct the power wheelchair toward the obstacles. Even so, haptic feedback did not strongly impress Lilian. She discussed the auditory and visual feedback more (and the combination of these). She potentially did not require the haptic feedback because she was responding appropriately to the other modes already. In contrast, Mark felt that the haptic feedback was too controlling and did not want the driving directions to be locked out. The other three residents did not voice concerns about feeling a loss of control with the haptic feedback. Interesting to note is that we wanted to encourage the experience of control for users by avoiding autonomous driving modes and by offering as many allowable directions to negotiate away from obstacles as possible, but some users such as Mark may still perceive this as restricting. However, the results found here sug- gest that some residents with cognitive impairment may not mind this form of haptic feedback and the momentary loss of control with the power wheelchair stopping and offering a limited set of allowed directions.

The use of warnings, as suggested by Mark, for nearby obstacles may be a good solution to enable more user control. Since auditory feedback may be best for capturing attention, an auditory prompt indicating the presence or locations of obstacles may be a viable solution. Additionally, a haptic warning may be put in place where gradually increasing force feedback is exerted through the joystick (versus a complete blocking) to resist user movements as the user nears obstacles. This proportional haptic feedback would be delivered before stopping the power wheelchair and locking directions of joystick movement. This type of warning would not be abrupt compared with the instantaneous blocking of directions and would alleviate the "unexpectedness" that Jim voiced. This proportional type of force feedback for manual joystick operation was previously discussed. The technology is still in development and has not been tested with the specified population of users with severe motor impairments [25-26] or in real environments [24-26].

Unimodal and multimodal warnings that use visual, auditory, and tactile modalities have been explored to improve automobile driving performance, such as warning alerts to prevent rear-end collisions [32,62]. Research indicates that incorporating alerting signals in all modalities (auditory, visual, or tactile) can decrease driver response times, although tactile alerts either unimodally or multimodally are useful to decrease driver response times because visual and auditory attention is already heavily used during driving [62].

The timing and other delivery features of warning prompts need to be explored further for power wheelchair operation. For example, a more detailed investigation is needed to elucidate the appropriate time to deliver prompts given the user's reaction time, driving speed, and proximity to the obstacles; the number of repetitions of auditory prompts to be given; or the ideal range of perceivable resistance for joystick movements. Another area needing to be examined further may be the ideal modality to be used in different driving scenarios, such as in a dining room, where multiple obstacles are close. Multiple auditory prompts for single directions in rapid succession may be confusing or ineffective if short-term memory is limited. Haptic feedback that allows the user to explore 
and "feel" the surrounding environment of obstacles may be more useful.

Further research is necessary to determine which prompt features are tolerated, safe, and effective for users with cognitive impairments. Conceivably, different users will have different abilities, including impaired vision or hearing, which will limit the usefulness of specific modalities or have specific preferences or environments of use such that some degree of customization at the assessment and provision level must be accommodated.

\section{Power Mobility and Resident Users}

Our focus was to evaluate how residents responded to the device in the real context of use, that is, in the longterm-care home environment following a training procedure similar to that used in clinical practice. While this approach may take longer than trials in a laboratory test course, we felt it would represent residents' experiences more realistically. In this protocol, we recognized that tailoring the driving training to the resident was essential, so we did not plan all sessions in advance but used the resident's self-identified mobility goals and items from the PIDA as a guide for training activities. We also recognized that for some residents, learning to use a power mobility device may take several months [45], so we did not plan to train until their skills reached a plateau.

The residents who participated in this study were not power wheelchair users and were not previously considered for power mobility by the long-term-care home staff because of cognitive and other issues that may restrict residents from operating conventional power wheelchairs safely and independently. These residents were ideal candidates for testing this device. Their driving performance indicated that with modifications, power wheelchairs may be operated safely and independently. Residents driving a collision-avoidance power wheelchair may take longer to achieve their targets, but they are self-mobilizing with the minimized risk of bumping into people or objects that could cause harm. Also, feedback offered by the multimodal interface may help them use collision-avoidance power wheelchairs more effectively and efficiently.

Some of the residents, including Lilian and Gerry, were able to learn new skills. Long-term training and practice with a device like the one tested might enable them to progress to using a conventional power wheelchair. Hence, the application of a power wheelchair with collisionavoidance and multimodal feedback features might be used as a training tool to allow a greater number of residents to experience safe and independent mobility. The device may also be useful as an assessment tool, especially for users who may potentially drive but whose ability is unclear. Power wheelchair users and therapists may have more confidence with testing a power wheelchair with added safety features. Two power mobility-training devices, the CALL (Communication, Access, Literacy, and Learning) Scotland Smart Wheelchair (Smile Rehab LTD; Newbury, Berkshire, United Kingdom) and the C300-TIRO (Permobil, International; Bolton, United Kingdom), are currently commercially available and have been tested with varied purposes and outcomes with children with severe disabilities [63-64] and children and adults with profound cognitive disabilities [65]. An area that needs to be explored further is whether special features such as collision detection or line following augment or hinder learning because users may require the feedback or self-directed activity to develop power wheelchair skills [66]. Researchers have developed and evaluated technology and training approaches primarily with children with different degrees of disability and adults with severe cognitive disabilities. However, much still needs to be explored related to older adults with mild or moderate cognitive impairments and the best training tools and strategies to enable power wheelchair use with this population.

\section{Study Limitations}

Testing was completed with a relatively small number of residents, so generalizability to the wider population of long-term-care residents with mild or moderate cognitive impairments is restricted. However, in studies of usability, testing with a small number of potential users (approximately five) is often recommended [33]. Testing with a small group can identify the majority of usability issues before developers can move to an improved design for further testing and can ideally balance resources and the number of issues identified [33].

One limitation of this study is that the residents included in the study were not current power wheelchair users. This may affect study results because the residents may be more motivated to use power mobility or respond more positively. They see use of a power wheelchair as a means to increase independence. However, we found that this was not necessarily the case because one subject, Mark, preferred his manual wheelchair. Also, because they are new to power wheelchairs and their use, they may not be able to compare or contrast features tested in this device with currently available power wheelchairs. 
However, as mentioned, residents were not considered candidates for currently available power wheelchairs and such a comparison would not be feasible.

Another limitation of this study is that the study device is a simulation of a future collision-avoidance power wheelchair, with the investigator acting as the sensors and intelligence. In this case, we evaluated the system under more ideal conditions than may be possible with the current state of development technology and artificial intelligence. Implementation of a system that can mimic the observational and decision-making abilities of a human has yet to be realized, so many more usability issues may arise when a prototype system rather than a simulation becomes available for evaluation. However, the value of using a simulated system with a population of older adult residents with cognitive impairments in the real-life setting is that it uncovers vital information about users' needs and responses to technology. With this information, further development is done without the complications of testing with less-developed prototypes with flaws that may result in a biased evaluation of the overall concepts being investigated.

\section{CONCLUSIONS}

Usability evaluation of a device consisting of a power wheelchair with collision-avoidance capability and auditory, visual, and simple haptic feedback to aid navigation demonstrated that the device is effective, efficient, and satisfying for long-term-care home residents with mild or moderate cognitive impairment. Future collision-avoidance power wheelchairs for this population might benefit from adding (1) auditory feedback; (2) visual indicators around the joystick controller to display the available directions of movement; (3) blocks to joystick movement in the directions of obstacles, with a consideration for applying proportional haptic feedback; and (4) increased driving speed to an average walking speed only if the technology can safely operate at that speed. Areas for further development include-

- Refining the delivery features of the multimodal feedback.

- Investigating the modes of feedback, ideal logic for navigation away from obstacles, and driving speed in different driving environments, such as wide-open spaces or spaces with many potential obstacles.

- Adding warning prompts.
- Integrating the multimodal interface with a collisionavoidance power wheelchair.

The simulated system was also found to be useful potentially as an assessment and training tool. Future evaluation will include testing the device as a training tool in addition to as an augmentative power mobility device to promote independence in a larger number of longterm-care residents who are currently mobility dependent.

\section{ACKNOWLEDGMENTS}

Author Contributions:

Study concept and design: R. H. Wang, A. Mihailidis, T. Dutta, G. R. Fernie.

Acquisition of data: R. H. Wang, T. Dutta.

Analysis and interpretation of data: R. H. Wang.

Drafting of manuscript: R. H. Wang.

Critical revision of manuscript for important intellectual content: R. H. Wang, A. Mihailidis, T. Dutta, G. R. Fernie.

Obtained funding: G. R. Fernie.

Administrative, technical, or material support: R. H. Wang, A. Mihailidis, T. Dutta, G. R. Fernie.

Study supervision: G. R. Fernie.

Financial Disclosures: The authors have declared that no competing interests exist.

Funding/Support: This material was based on work supported by the Canadian Institutes of Health Research Operating Grant, MOP 57696, and Toronto Rehabilitation Institute. Toronto Rehabilitation Institute receives funding under the Provincial Rehabilitation Research Program from the Ministry of Health and Long-Term Care in Ontario. Equipment and space were funded, in part, with grants from the Canada Foundation for Innovation and the Province of Ontario. A Canadian Institutes of Health Research Canada Graduate Scholarship Master's Award, an Ontario Graduate Scholarship, Toronto Rehabilitation Institute, and the University of Toronto funded the first author. Dynamis Mobility donated the Nomad power wheelchair used in this study. Additional Contributions: Rosalie $\mathrm{H}$. Wang is now a Postdoctoral Fellow with the Intelligent Assistive Technology and Systems Laboratory at the University of Toronto and Toronto Rehabilitation Institute. Institutional Review: The academic hospital research ethics board approved this article's methodology prior to the start of participant recruitment and testing.

Participant Follow-Up: The authors do not plan to inform the participants of the publication of this study.

\section{REFERENCES}

1. Bourret EM, Bernick LG, Cott CA, Kontos PC. The meaning of mobility for residents and staff in long-term-care facilities. J Adv Nurs. 2002;37(4):338-45. [PMID: 11872103] DOI:10.1046/j.1365-2648.2002.02104.X 
2. Banerjee A. Long-term care in Canada: An overview. In: Armstrong P, Boscoe M, Clow B, Grant K, HaworthBrockman M, Jackson B, Pederson A, Seeley M, Springer J, editors. A place to call home: Long-term care in Canada. Winnipeg (Canada): Fernwood Publishing; 2009. p. 29-57.

3. Shields M. Use of wheelchairs and other mobility support devices. Health Rep. 2004;15(3):37-41. [PMID: 15208888]

4. Brechtelsbauer DA, Louie A. Wheelchair use among longterm care residents. Ann Longterm Care. 1999;7(6):213-20.

5. Bourbonniere MC, Fawcett LM, Miller WC, Garden J, Mortenson WB. Prevalence and predictors of need for seating intervention and mobility for persons in long-term care. Can J Aging. 2007;26(3):195-204. [PMID: 18238726$]$ DOI:10.3138/cja.26.3.195

6. Brandt A, Iwarsson S, Ståhle A. Older people’s use of powered wheelchairs for activity and participation. J Rehabil Med. 2004;36(2):70-77. [PMID: 15180221] DOI:10.1080/16501970310017432

7. Mortenson WB, Miller WC, Boily J, Steele B, Odell L, Crawford EM, Desharnais G. Perceptions of power mobility use and safety within residential facilities. Can J Occup Ther. 2005;72(3):142-52. [PMID: 15988961]

8. May M, Rugg S. Electrically powered indoor/outdoor wheelchairs: Recipients' views of their effects on occupational performance and quality of life. Br J Occup Ther. 2010;73(1):2-12.

9. Hardy P. Examining the barriers: Powered wheelchair mobility for people with cognitive and/or sensory impairments. Proceedings of the ARATA 2004 National Conference; 2004 Jun 2-4; Melbourne, Australia. Melbourne (Australia): ARATA Inc. Available from:

http://www.arata.org.au/arataconf04/abstracts/hardy.html

10. Oliver D, Connelly JB, Victor CR, Shaw FE, Whitehead A, Genc Y, Vanoli A, Martin FC, Gosney MA. Strategies to prevent falls and fractures in hospitals and care homes and effect of cognitive impairment: Systematic review and metaanalyses. BMJ. 2007;334(7584):82. [PMID: 17158580] DOI:10.1136/bmj.39049.706493.55

11. Neyens JC, Dijcks BP, Twisk J, Schols JM, Van Haastregt JC, Van den Heuvel WJ, De Witte LP. A multifactorial intervention for the prevention of falls in psychogeriatric nursing home patients, a randomised controlled trial (RCT). Age Ageing. 2009;38(2):194-99. [PMID: 19221130]

12. Fehr L, Langbein WE, Skaar SB. Adequacy of power wheelchair control interfaces for persons with severe disabilities: A clinical survey. J Rehabil Res Dev. 2000;37(3): 353-60. [PMID: 10917267]

13. Simpson RC, LoPresti EF, Cooper RA. How many people would benefit from a smart wheelchair? J Rehabil Res Dev. 2008;45(1):53-71. [PMID: 18566926]

DOI:10.1682/JRRD.2007.01.0015
14. Simpson RC. Smart wheelchairs: A literature review. J Rehabil Res Dev. 2005;42(4):423-36. [PMID: 16320139] DOI:10.1682/JRRD.2004.08.0101

15. Mihailidis A, Elinas P, Boger J, Hoey J. An intelligent powered wheelchair to enable mobility of cognitively impaired older adults: An anticollision system. IEEE Trans Neural Syst Rehabil Eng. 2007;15(1):136-43. [PMID: 174368886] DOI:10.1109/TNSRE.2007.891385

16. Viswanathan P, Boger J, Hoey J, Elinas P, Mihailidis A. The future of wheelchairs: Intelligent collision avoidance and navigation assistance. Geriatr Aging. 2007;10(4):253-56.

17. Wang RH, Gorski SM, Holliday PJ, Fernie GR. Evaluation of a contact sensor skirt for an anti-collision power wheelchair for older adult nursing home residents with dementia: Safety and mobility. Assist Technol. Forthcoming 2011.

18. Swartz J, Mihailidis A. Investigating the efficacy of using an anti-collision system on a powered wheelchair to improve safety and mobility for older adults with dementia [master's thesis]. [Toronto (Canada)]: Occupational Science and Occupational Therapy, University of Toronto; 2009.

19. Maki O, Topo P. User needs and user requirements of people with dementia: Multimedia application for entertainment. In: Topo P, Östlund B, editors. Dementia, design and technology. Fairfax (VA): ISO Press; 2009. p. 61-75.

20. Orpwood R, Bjørneby S, Hagen I, Mäki O, Faulkner R, Topo P. User involvement in dementia product development. Dementia. 2004;3(3):263-79.

DOI:10.1177/1471301204045160

21. Nilsson L, Nyberg PJ. Single-switch control versus powered wheelchair for training cause-effect relationships: Case studies. Technol Disabil. 1999;11(1-2):35-38.

22. Pellegrini N, Guillon B, Prigent H, Pellegrini M, Orlikovski D, Raphael JC, Lofaso F. Optimization of power wheelchair control for patients with severe Duchenne muscular dystrophy. Neuromuscul Disord. 2004;14(5):297-300.

[PMID: 15099587]

DOI:10.1016/j.nmd.2004.02.005

23. Dicianno BE, Spaeth DM, Cooper RA, Fitzgerald SG, Boninger ML. Advancements in power wheelchair joystick technology: Effects of isometric joysticks and signal conditioning on driving performance. Am J Phys Med Rehabil. 2006;85(8):631-39. [PMID: 16865017]

DOI:10.1097/01.phm.0000228519.54763.b4

24. Protho JL, LoPresti EF, Brienza DM. An evaluation of an obstacle avoidance force feedback joystick. Proceedings of the Annual RESNA Conference; 200028 Jun-2 Jul; Orlando, FL. Arlington (VA): RESNA Press. p. 447-49.

25. Fattouh A, Sahnoun M, Bourhis G. Force feedback joystick control of a powered wheelchair: Preliminary study. Proceedings of the IEEE International Conference on Systems, Man and Cybernetics, vol. 3; 2004 Oct 10-13; The Hague, the Netherlands. Los Alamitos (CA): IEEE; 2004. p. 2640-45. 
26. Bourhis G, Sahnoun M. Assisted control mode for a smart wheelchair. Proceedings of the IEEE 10th International Conference on Rehabilitation Robotics; 2007 Jun 13-15; Noordwijk, the Netherlands. Los Alamitos (CA): IEEE; 2007. p. 158-63.

27. Hayward V, Astley OR, Cruz-Hernandez M, Grant D, Robles-De-La-Torre G. Haptic interfaces and devices. Sensor Rev. 2004;24(1):16-29. DOI:10.1108/02602280410515770

28. Sarter NB. Multimodal information presentation: Design guidance and research challenges. Int J Ind Ergon. 2006; 36(5):439-45. DOI:10.1016/j.ergon.2006.01.007

29. Laurienti PJ, Burdette JH, Maldjian JA, Wallace MT. Enhanced multisensory integration in older adults. Neurobiol Aging. 2006;27(8):1155-63. [PMID: 16039016] DOI:10.1016/j.neurobiolaging.2005.05.024

30. Mihailidis A, Boger JN, Craig T, Hoey J. The COACH prompting system to assist older adults with dementia through handwashing: An efficacy study. BMC Geriatr. 2008;8:28. [PMID: 18992135]

DOI:10.1186/1471-2318-8-28

31. Gray R. Multisensory information in the control of complex motor actions. Curr Dir Psychol Sci. 2008;17(4):244-48. DOI:10.1111/j.1467-8721.2008.00583.x

32. Spence C, Ho C. Multisensory warning signals for event perception and safe driving. Theor Issues Ergon Sci. 2008; 9(6):523-54. DOI:10.1080/14639220701816765

33. Tullis T, Albert B. Measuring the user experience. Burlington (MA): Morgan Kaufmann; 2008.

34. Dawson DR, Kaiserman-Goldenstein E, Chan R, Gleason J. Power-Mobility Indoor Driving Assessment (PIDA) [Internet]. Hamilton (Canada): McMaster University; 2006 [cited 2008 Feb 12]. Available from: http://fhs.mcmaster.ca/powermobility/pida.htm.

35. Hart SG, Staveland LE. Development of NASA-TLX (Task Load Index): Results of empirical and theoretical research. In: Hancock PA, Meshkati B, editors. Advances in psychology: Human mental workload. Amsterdam (the Netherlands): North Holland Press; 1988. p. 239-50. DOI:10.1016/S0166-4115(08)62386-9

36. Demers L, Weiss-Lambrou R, Ska B. The Quebec User Evaluation of Satisfaction with Assistive Technology (QUEST 2.0): An overview and recent progress. Technol Disabil. 2002;14(3):101-5.

37. Day HI, Jutai J. Psychosocial Impact of Assistive Devices Scale: A tool for evaluating the psychological benefits of rehabilitation technologies. London (Canada): University of Western Ontario; 2003.

38. Creswell JW, Plano Clark VL. Designing and conducting mixed methods research. Thousand Oaks (CA): Sage Publications; 2007.

39. Canadian Standards Association. CAN/CSA-ISO 14971:01 Medical devices-Application of risk management to medi- cal devices. Adopted without modification from ISO 14971:2000; 2001.

40. Folstein MF, Folstein SE, McHugh PR, Fanjiang G. MiniMental State Examination user's guide. Odessa (FL): Psychological Assessment Resources; 2001.

41. Nielsen J, Landauer TK. A mathematical model of the finding of usability problems. Proceedings of INTERACT '93 and CHI '93 Conference on Human Factors in Computing Systems; 1993 Apr 24-29; Amsterdam, the Netherlands. New York (NY): ACM; 1993. New York: ACM. p. 206-13.

42. Brighton C. Rules of the road. Rehab Manag. 2003;16(3): 18-21. [PMID: 12741254]

43. Colarusso RP, Hammill DD, Martin NA. MVPT-3-Examiner's manual. 3rd ed. Novata (CA): Academic Therapy Publications; 2003.

44. Dawson D, Chan R, Kaiserman E. Development of the power-mobility indoor driving assessment for residents of long-term care facilities: A preliminary report. Can J Occup Ther. 1994;61(5):269-76.

45. Hall K, Partnoy J, Tenenbaum S, Dawson DR. Power mobility driving training for seniors: A pilot study. Assist Technol. 2005;17(1):47-56. [PMID: 16121645]

46. Horberry T, Anderson J, Regan MA, Triggs TJ, Brown J. Driver distraction: The effects of concurrent in-vehicle tasks, road environment complexity and age on driving performance. Accid Anal Prev. 2006;38(1):185-91.

[PMID: 16226211]

DOI:10.1016/j.aap.2005.09.007

47. Matthews R, Legg S, Charlton S. The effect of cell phone type on drivers subjective workload during concurrent driving and conversing. Accid Anal Prev. 2003;35(4):451-57.

[PMID: 12729809]

DOI:10.1016/S0001-4575(02)00023-4

48. Sullivan JM, Bärgman J, Adachi G, Schoettle B. Driver performance and workload using a night vision system. Proceedings of the 4th International Driving Symposium on Human Factors in Driver Assessment, Training and Vehicle Design [CD-ROM]; 2007 Jul 9-12; Stevenson, WA. Iowa City (IA): University of Iowa, Public Policy Center. p. 519-26.

49. Parikh SP, Grassi V Jr, Kumar V Jr, Okamoto J Jr. Integrating human inputs with autonomous behaviours on an intelligent wheelchair platform. IEEE Intell Syst. 2007;22(2): 33-41. DOI:10.1109/MIS.2007.36

50. Demers L, Weiss-Lambrou R, Ska B. Quebec User Evaluation of Satisfaction with Assistive Technology QUEST 2.0. New York (NY): Marcia J. Scherer PhD Institute for Matching Person and Technology; 2000.

51. Brandt A, Iwarsson S. Do certain groups of older people benefit the most from the use of powered wheelchairs? In: Winters J, editor. Proceedings of the RESNA Conference; 
2001 Jun 22-26; Reno, Nevada. Arlington (VA): RESNA Press; 2001. p. 212-14.

52. Trefler E, Fitzgerald SG, Hobson DA, Bursick T, Joseph R. Outcomes of wheelchair systems intervention with residents of long-term care facilities. Assist Technol. 2004; 16(1):18-27. [PMID: 15257146$]$ DOI:10.1080/10400435.2004.10132071

53. Devitt R, Chau B, Jutai JW. The effect of wheelchair use on the quality of life of persons with multiple sclerosis. Occup Ther Health Care. 2003;17(3-4):63-79.

54. Buning ME, Angelo JA, Schmeler MR. Occupational performance and the transition to powered mobility: A pilot study. Am J Occup Ther. 2001;55(3):339-44.

[PMID: 11723976]

DOI:10.5014/ajot.55.3.339

55. Charness N, Holley P. Human factors and environmental support in Alzheimer's disease. Aging Ment Health. 2001; 5(Suppl 1):S65-73. [PMID: 11513500$]$

DOI:10.1080/713650000

56. Wang RH, Kontos PC, Holliday PJ, Fernie GR. The experiences of using an anti-collision power wheelchair for three long-term care residents with mild cognitive impairment. Disabil Rehabil Assist Technol. 2011;6(4):347-63.

[PMID: 20846075] DOI:10.3109/17483107.2010.519096

57. Knapp BG, Hall BJ. High performance concerns for the TRACKWOLF system (ARI Research Note 91-14). Alexandria, (VA): ARI; 1990.

58. Moroney WF, Biers DW, Eggemeier FT, Mitchell JA. A comparison of two scoring procedures with the NASA Task Load Index in a simulated flight task. Proceedings of the IEEE 1992 National Aerospace and Electronics Conference, vol. 2; 1992 May 18-22; Dayton, OH. Los Alamitos (CA): IEEE; 1992. p. 734-40. DOI:10.1109/NAECON.1992.220513

59. Miles-Tapping C, MacDonald LJ. Lifestyle implications of power mobility. Phys Occup Ther Geriatr. 1994;12(4):31-49.

60. Trefler E, Hobson DA, Taylor SJ, Monahan LC, Shaw CG. Seating and mobility for persons with physical disabilities. Tucson (AZ): Therapy Skill Builders; 1993.

61. Lindenberger U, Lövdén M, Schellenbach M, Li SC, Krüger A. Psychological principles of successful aging technologies: A mini-review. Gerontology. 2008;54(1):59-68.
[PMID: 18259095]

DOI:10.1159/000116114

62. Scott JJ, Gray R. A comparison of tactile, visual, and auditory warnings for rear-end collision prevention in simulated driving. Hum Factors. 2008;50(2):264-75. [PMID: 18516837] DOI:10.1518/001872008X250674

63. CALL Centre. Smart wheelchair user manual V. 5: Communication aids for language and learning centre; CALL Centre; 2000 [cited 201010 January]; Available from: http://www.callscotland.org.uk/about-us/Projects/SmartWheelchair/

64. Nisbet P, Craig J, Odor P, Aitken S. "Smart” wheelchairs for mobility training. Technol Disabil. 1996;5:49-62. DOI:10.1016/1055-4181(96)00147-1

65. Nilsson L. Driving to learn. The process of growing consciousness of tool use-A grounded theory of de-plateauing [dissertation]. [Lund (Sweden)]: Faculty of Medicine, Department of Health Sciences, Division of Occupational Therapy and Gerontology, Lund University; 2007.

66. Durkin J. The need for the development of a child led assessment tool for powered mobility users. Technol Disabil. 2002;14(4):163-71.

Submitted for publication August 10, 2010. Accepted in revised form January 10, 2011.

This article and any supplementary material should be cited as follows:

Wang RH, Mihailidis A, Dutta T, Fernie GR. Usability testing of multimodal feedback interface and simulated collision-avoidance power wheelchair for long-term-care home residents with cognitive impairments. J Rehabil Res Dev. 2011;48(7):801-22.

DOI:10.1682/JRRD.2010.08.0147

ResearcherID: Rosalie H. Wang, PhD, BSc (OT): D-37432011

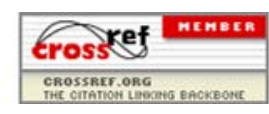


